\title{
AS MÁSCARAS DE JON SNOW: diferentes identidades do personagem da série Game of Thrones ${ }^{I}$
}

\section{JON SNOW'S MASKS: different identities of Game of Thrones series' character}

\author{
Paloma Rodrigues Destro COUTO ${ }^{2}$ \\ José Luiz RIBEIRO ${ }^{3}$
}

Resumo: Este trabalho pretende analisar questões identitárias presentes na série norteamericana Game of Thrones, com enfoque no personagem Jon Snow (Kit Harington). O aparato teórico necessário é pautado nas ideias de Hall (2003), Woodward (2011), Silva (2011), Kellner (2001), Bhabha (1998), dentre outros. A metodologia é focada nos diálogos entre os personagens. Percebe-se, nas três temporadas já exibidas, que a identidade de Jon é alterada de acordo com as circunstâncias externas, sendo construída segundo o ambiente em que se encontra, as relações estabelecidas com a alteridade e a luta pela sobrevivência. Assim, percebemos a importância de produtos audiovisuais como o analisado no contexto de mediações identitárias, já que a série acaba por reproduzir o que se vive na contemporaneidade: apesar de ambientada na Idade Média, possui abordagens atuais. O que motiva uma ampla aceitação pelo público, que a elevou ao patamar de grande sucesso.

Palavras-chave: Identidade; Alteridade; Game of Thrones; Jon Snow.

Abstract: This article has sought to analyze the questions of identity that exist in the Northamerican series Game of Thrones, focused on Jon Snow (Kit Harrigton) character. The

\footnotetext{
${ }^{1}$ Artigo apresentado originalmente no GT Teorías y estudios de la imagen audiovisual do VII Seminário Latinoamericano de Investigação da Comunicação.

2 Programa de Pós-Graduação em Comunicação da Universidade Federal de Juiz de Fora. E-mail: palomadestro@hotmail.com

3 Programa de Pós-Graduação em Comunicação da Universidade Federal de Juiz de Fora. E-mail: zeluiz@acessa.com
} 


\section{míDiA \\ e

required theoretical apparatus is based upon the ideas of Hall (2003), Woodward (2011), Silva (2011), Kellner (2001), Bhabha (1998), and others. The methodology is focused on the character's dialogue. We noticed, in the three seasons already exhibited, that Jon's identity is changed according to external factors, the environment he is in, the alterity and the struggle for surviving. Thus, we noticed the importance of audiovisual products such as the ones analyzed in the identity mediation context, as the series reproduces what we live in contemporary society: despite set on the Middle Age, it has actual approaches. This is the motivation of the public's extensive acceptance, that turned it into a great success.

Keywords: Identity; Alterity; Game of Thrones; Jon Snow.

\section{Introdução}

Os acontecimentos da vida social sempre tiveram representações em diversos meios, como na literatura, na televisão, no teatro. O cinema é um grande exemplo. O historiador Marc Ferro discute em seu texto "O filme - Uma contra-análise da sociedade?" 4 o valor que as produções cinematográficas têm como fonte de pesquisa histórica.

Por muitos anos, segundo Ferro, os historiadores se negaram a analisar filmes, vendoos como produtos para iletrados, voltados para as massas, manipulados (devido à edição), uma máscara do real. Com o passar do tempo, de acordo com Ferro, percebeu-se que o filme é capaz de testemunhar.

Ela [a câmara] descobre o segredo, ela ilude os feiticeiros, tira as máscaras, mostra o inverso de uma sociedade, seus lapsus. É mais do que é preciso para que, após a hora do desprezo, venha a da desconfiança, do temor. [...] A ideia de que um gesto poderia ser uma frase, esse olhar, um longo discurso, é totalmente insuportável: significaria que a imagem, as imagens, esses passantes, essa rua, esse soluço, esse juiz distraído, esse pardieiro em ruínas, essa jovem assustada, constituem a matéria de uma outra história que não a História, uma contra-análise da sociedade (FERRO, disponível em:

<http://www.educacaopublica.rj.gov.br/oficinas/historia/reverso/downloads/MarcFer ro.pdf $>$. Acesso em 28 jul. 2013).

\footnotetext{
${ }^{4}$ Artigo 


\section{míDiA

Para Ferro, é necessário acionar outros saberes para se compreender o que é mostrado na produção cinematográfica. O filme, assim, deve ser associado à época em que foi produzido. A hipótese do autor é que "o filme, imagem ou não da realidade, documento ou ficção, intriga autêntica ou pura invenção, é História; o postulado? Que aquilo que não se realizou, as crenças, as intenções, o imaginário do homem, é tanto a História quanto a História"

(FERRO, disponível

em: <http://www.educacaopublica.rj.gov.br/oficinas/historia/reverso/downloads/MarcFerro.pdf>. Acesso em 28 jul. 2013).

O filósofo e crítico cultural Slavoj Zizek também acredita que os filmes vão reproduzir situações atuais, principalmente no que concerne a produções hollywoodianas. Um exemplo é o artigo "El Minority Report de Gerhard Schroeder y sus Consecuencias"5. Nele, Zizek analisa o filme The Minority Report (2003). No longa, três humanos adquirem a capacidade de prever o futuro e são acionados pelas autoridades para deter criminosos antes que cometam seu crime.

Zizek relaciona a produção ao governo Bush da época e sua "guerra ao terror": a filosofia americana de política internacional, lançada pela Casa Branca em 2002, assegurava direitos de intervenção dos EUA em países considerados pelos norte-americanos como potencial inimigo.

Si uno transpone esta premisa a las relaciones internacionales, ¿no consigue uno el cuadro exacto que la "doctrina Bush" (o, más bien, Cheney) declaró ahora públicamente como la "filosofía" americana oficial de política internacional [...]? América tiene el derecho a golpear "preventivamente", es decir, para atacar países que no plantean una amenaza directa a E.U., pero que podrían representar una amenaza en el futuro previsible; aunque los Estados Unidos deben buscar coaliciones internacionales ad hoc para tales ataques, se reservan el derecho para actuar independientemente sin el apoyo internacional (ZIZEK, disponível em: <http://www.geocities.ws/zizekencastellano/artSchroeer.html>. Acesso em: 28 de julho de 2003).

\footnotetext{
${ }^{5}$ Artigo disponível em: <http://www.geocities.ws/zizekencastellano/artSchroeer.html>. Acesso em: 28 de julho de 2003.
} 


\section{míDiA \\ eCOt: \\ DiAno}

Há, assim, a necessidade de entendermos o quadro da realidade em que as produções se inserem para compreendermos o que elas representam. Isto está de acordo com o que Douglas Kellner adota como tese no livro “A Cultura da Mídia” (2001):

a compreensão dos filmes populares de Hollywood, de Madonna, da MTV, do rap, dos filmes atuais sobre os negros e dos programas de notícia e entretenimento da televisão pode ajudar-nos a entender nossa sociedade contemporânea. Ou seja, entender o porquê da popularidade de certas produções pode elucidar o meio social em que elas nascem e circulam, podendo, portanto, levar-nos a perceber o que está acontecendo nas sociedades e nas culturas contemporâneas (KELLNER, 2001, p.14).

É neste sentido que enquadramos nosso objeto de análise. A série Game of Thrones alcançou um sucesso mundial, registrando altos índices de audiência. Somente nos EUA, mais de quatro milhões de espectadores assistiram ao início da terceira temporada ${ }^{6}$, em março de 2013. Mas o que a série traz, no âmbito comunicacional, para agregar tantos espectadores e fãs?

Através dos veículos comunicacionais, a população terá acesso a representações identitárias, símbolos e posicionamentos sobre a sociedade. Kellner (2001) explica ainda que a cultura da mídia vai fornecer materiais para que as pessoas possam formar sua identidade, construindo seu senso de classe, nacionalidade, etnia. A cultura da mídia vai definir valores e fornecer símbolos e mitos que colaboram na construção de modelos para as pessoas, que vão se inserir nas sociedades representadas.

Mas de que maneira podemos identificar essas representações em produtos audiovisuais? O objetivo deste trabalho é, portanto, mostrar como uma produção atual e de sucesso é capaz de fornecer situações identitárias contemporâneas para o seu público, apesar de ambientada na Idade Média. Para isso, utilizamos como objeto o personagem Jon Snow

\footnotetext{
6 Informação disponível em <http://exame.abril.com.br/negocios/noticias/game-of-thrones-a-arma-da-hbocontra-os-zumbis-deu-certo>. Acesso em 28 de julho de 2013.
} 


\section{míDiA \\ eco \\ DiAno}

(Kit Harigton) que, durante as três temporadas já exibidas, apresentou mudanças em sua identidade.

Entendermos de que maneira um produto midiático como Game of Thrones fornece representações sobre o sujeito contemporâneo é de extrema relevância para compreendermos o papel de produções audiovisuais como mediadoras identitárias para a audiência.

\section{Identidades fragmentadas}

Não se pode dizer atualmente que existe uma identidade fixa, rígida, imutável. A globalização, ao encurtar distâncias, aproximar diferentes povos e, com isso, intensificar as trocas culturais, trouxe mudanças também na concepção de identidade do sujeito. Tudo agora é rápido, mutável, fluido.

Quanto mais a vida social se torna mediada pelo mercado global de estilos, lugares e imagens, pelas viagens internacionais, pelas imagens da mídia e pelos sistemas de comunicação globalmente interligados, mais as identidades se tornam desvinculadas - desalojadas - de tempos, lugares, histórias e tradições específicos e parecem "flutuar" livremente. Somos confrontados por uma gama de diferentes identidades [...], dentre as quais parece possível fazer uma escolha (HALL, 2003, p.75).

O indivíduo moderno é, portanto, fragmentado, assim como sua identidade, que vai sendo construída através do estabelecimento de diferenças com o outro, com a alteridade. Este movimento não é algo binário (ruim/bom, por exemplo) e não pode ser fixado, na medida em que as identidades estão em constante mutação, fazendo parte de um processo que se intensifica ao entrar em contato com o outro. É a relação entre os sujeitos na construção de suas identidades que vai apontar as diferenças existentes.

A diferença pode ser construída negativamente - por meio da exclusão ou da marginalização daquelas pessoas que são definidas como "outros" ou forasteiros. Por outro lado, ela pode ser celebrada como fonte de diversidade, heterogeneidade e hibridismo, sendo vista como enriquecedora: é o caso dos movimentos sociais que buscam resgatar as identidades sexuais dos constrangimentos da norma e celebrar a diferença (WOODWARD, 2011, p.50-51). 


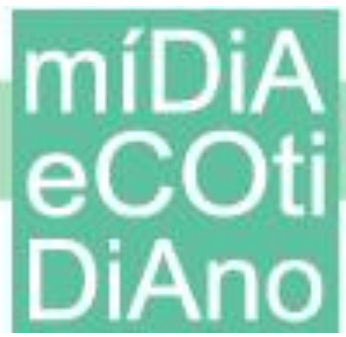

PPGMC

Tomaz Tadeu da Silva (2011) atenta para o fato de a identidade e a diferença possuírem uma relação de estreita dependência. Para o autor, afirmações sobre identidade só fazem sentido quando existem diferenças (em um local imaginário onde todos tivessem a mesma identidade, não faria sentido afirmar esta identidade. $\mathrm{O}$ exemplo que o autor dá é falarse, em nossa sociedade, que somos humanos - é irrelevante por esta ser uma característica comum aos sujeitos do meio social).

Silva também pondera que afirmações de diferenças acabam por depender de uma cadeia de declarações negativas sobre outras identidades: "Dizer que 'ela é chinesa' significa dizer que 'ela não é argentina', 'ela não é japonesa', etc., incluindo a afirmação de que 'ela não é brasileira', isto é, que ela não é o que eu sou" (SILVA, 2011, p.75).

$\mathrm{O}$ autor entende ainda identidade e diferença como criações linguística, isto é, não existem prontas na natureza, não são essências; elas devem ser produzidas dentro do mundo cultural e social, sendo, portanto, criadas.

A articulação das identidades e das diferenças culturais promove o que Homi Bhabha (1998) chama de "entre-lugares". Estes são resultado da fluidez identitária existente também nas fronteiras que demarcam os domínios do Eu e do Outro. Para Bhabha, os "entre-lugares" fornecem o ambiente para que sejam elaboradas estratégias de subjetivação que vão iniciar novos signos de identidade e postos de contestação e colaboração: "É na emergência dos interstícios - a sobreposição e o deslocamento de domínios da diferença - que as experiências intersubjetivas e coletivas de nação [nationness], o interesse comunitário ou o valor cultural são negociados" (BHABHA, 1998, p.20).

Os embates existentes nos "entre-lugares" são fruto, portanto, de uma negociação em andamento, que emerge em momentos de transformação. A fronteira, não mais fixa, "se torna o lugar a partir do qual algo começa a se fazer presente em um movimento não dissimilar ao da articulação ambulante, ambivalente [...]" (BHABHA, 1998, p.24).

Podemos pensar que as identidades, além de construídas através das relações, são representações que se dão, para Stuart Hall, quando se pensa o sentido de nação. Para o autor, 


\section{míDiA

nós não nascemos com as identidades nacionais, mas elas são construídas e transformadas por representações. A nação vem carregada de sentidos, sendo, portanto, um sistema de representação cultural capaz de formar identidades.

As culturas nacionais, ao produzir sentidos sobre 'a nação', sentidos com os quais podemos nos identificar, constroem identidades. Esses sentidos estão contidos nas estórias que são contadas sobre a nação, memórias que conectam seu presente com o seu passado e imagens que delas são construídas (HALL, 2003, p.51).

As identidades, portanto, são fruto de narrativas que se fazem acerca do que é ser um determinado tipo de indivíduo. E é a partir dessas narrativas que as pessoas constroem o que seria sua nação. Para Benedict Anderson, a identidade nacional é uma "comunidade imaginada", isto é, existe uma relação estabelecida com aqueles com quem se compartilha uma história, a memória do passado. Há um movimento de projeção para algo maior, que seria a nação, a comunidade. Imaginada, portanto, por ser projetada.

$\mathrm{Na}$ formação dessa comunidade surge a identificação e o pertencimento. Não existe, apesar da ideia de nação, algo unificado; pelo contrário, há diversidade cultural, grupos diferentes compartilhando locais, sentidos, experiências. Dessa maneira, nos localizamos como pertencentes de algum grupo, algum local: "Todos nós nos originamos e falamos a partir de 'algum lugar': somos localizados - e neste sentido até os mais 'modernos' carregam traços de uma etnia” (HALL, 2003, p.83).

A televisão é um dos meios capazes de contar a história de povos e nações, tanto do presente quanto do passado. Segundo Jesús Martín-Barbero (2003), a televisão é o meio que mais permitiu o acesso à grande variedade de experiências humanas, de situações, de povos e de países. Mas, ao mesmo tempo, é também o que mais controlou essa variedade, já que é capaz de moldar as identidades para o seu espectador:

Ao conectar o espetáculo com a cotidianidade, o modelo hegemônico de televisão imbrica em seu próprio modo de operação um dispositivo paradoxal de controle das diferenças: uma aproximação ou familiarização que, explorando as semelhanças superficiais, acaba nos convencendo de que, 
se nos aproximarmos o bastante, até as mais 'distantes', as mais distanciadas no espaço e no tempo, se parecem muito conosco; e um distanciamento ou exotização que converte o outro na estranheza mais radical e absoluta, sem qualquer relação conosco, sem sentido para o nosso mundo. (MARTíNBARBERO, 2003, p.264-265, grifo do autor)

Não é viável, então, pensarmos que um produto audiovisual como a série norteamericana Game of Thrones, mesmo remetendo à Idade Média, não funciona também como uma forma de reprodução da fragmentação identitária atual? Não seria o moderno mascarado de medieval?

\section{Game of Thrones}

Game of Thrones (Guerra dos Tronos) é uma série de televisão americana criada por David Benioff e D.B. Weiss para a emissora HBO. A história é baseada na série literária “As Crônicas de Gelo e Fogo", de autoria de George R.R. Martin, sendo o título derivado do primeiro livro da série, "A Guerra dos Tronos". A primeira temporada estreou em 17 de abril de 2011, a segunda em $1^{\circ}$ de abril de 2012 e a terceira, em 31 de março de 2013.

A história se passa na ilha de Westeros, localidade que era ocupada por sete reinos independentes, até ser dominada por Aegon Targaryen, que as submeteu à sua casa e ao seu Trono de Ferro, formando uma só nação. Com isso, os Sete Reinos se tornaram sete casas juramentadas ao rei: Targaryen, Baratheon, Stark, Lannister, Greyjoy, Tully e Tyrell. Após uma grande guerra, conhecida como a Batalha do Tridente, a Casa Targaryen perde seu domínio e Robert Baratheon (Mark Addy) ocupa o Trono de Ferro.

Os primeiros episódios da série tratam da relação entre Robert, agora rei, e seu grande amigo Eddard "Ned" Stark (Sean Bean). A realeza vai até o Norte para convencer Ned a ser sua nova Mão do Rei (denominação dada ao principal conselheiro do monarca) na capital do reino, Porto Real. Eddard, contrariado, vai morar na corte com suas duas filhas, e lá encontra problemas e conspirações encabeçadas, principalmente, pela rainha Cersei (Lena Headey) e 


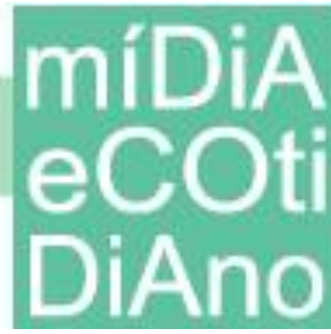

seu irmão gêmeo, Jaime (Nikolaj Coster-Waldau), ambos da casa Lannister. Com a morte posterior de Robert, Westeros se torna o campo de batalha de uma guerra entre as casas na busca pelo Trono de Ferro.

Paralela a isso, nas terras do Norte, existe a Muralha. Ela é guardada pela brigada militar Patrulha da Noite, composta por integrantes denominados Irmãos Juramentados, que protegem o local e, consequentemente, os Sete Reinos, das ameaças que existam além do monumento, como criaturas sobrenaturais e outros povos. A maioria dos integrantes da Patrulha se oferece de maneira voluntária e os desertores são punidos com a morte.

Os Irmãos Juramentados precisam abdicar de alguns aspectos cotidianos para ingressas na Patrulha: "exige-se de todos os patrulheiros algo parecido com o celibato: eles juram que jamais se casarão, terão filhos ou serão proprietários de terras, para evitar que tenham outra preocupação além de proteger a Muralha” (SZKLARZ, 2013, p.40).

É nesta ambientação que se encontra Jon Snow, nosso objeto de análise. Jon é filho bastardo de Ned Stark com uma mulher cuja identidade é desconhecida e cresceu em Winterfell (sede da Casa Stark). Preterido pela matriarca dos Starks, Jon decide seguir os passos de seu tio Benjen (Joseph Mawle), que é integrante da Patrulha da Noite, e se voluntaria para proteger a Muralha ainda no início da primeira temporada.

Os patrulheiros acham que estão ali para impedir uma invasão dos Selvagens povos que vivem além da Muralha. Mas Jon Snow [...] não acredita nisso. Ele crê que os principais inimigos, na verdade, são os Outros - criaturas inumanas que matam pessoas e as transformam em mortos-vivos (SZKLARZ, 2013, p.40).

Na segunda temporada, Jon sai em uma expedição ao norte da Muralha com o intuito de investigar, juntamente com outros Irmãos Juramentados, o desaparecimento de diversas patrulhas, dentre elas uma liderada por Benjen. Os Irmãos armam acampamento, mas Jon segue no grupo encabeçado por Qhorin Meia-Mão (Simon Armstrong), que tenta descobrir se Mance Rayder (Ciaran Hinds), o líder dos selvagens, planeja um ataque à Patrulha da Noite. 


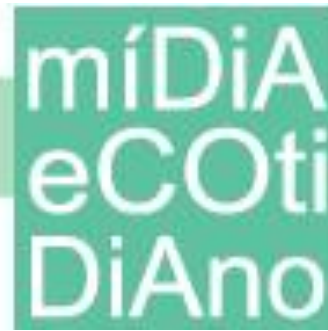

PPGMC

No caminho, Jon liberta uma selvagem que capturaram, Ygritte (Rose Leslie), que auxilia alguns companheiros a descobrir onde estavam os patrulheiros. Todos os Irmãos do grupo de Jon são mortos, menos ele e Qhorin, o qual ordena que Jon se una aos selvagens para descobrir seus segredos, se passando por um desertor. Para convencer os moradores além da Muralha de que agora é um deles, Jon mata Qhorin e é aceito no grupo.

É nesse contexto que se situa nossa análise da personagem. Propomos verificar as diferentes identidades assumidas por Jon desde que se tornou um Irmão Juramentado da Patrulha da Noite até o momento em que retorna à Muralha, após viver como selvagem durante a terceira temporada.

\section{Aspectos metodológicos}

A análise é direcionada para o movimento dialógico da expressão dos personagens. Os diálogos são tomados por nós como elementos condicionantes da narrativa. Nossa preocupação aqui não é, então, com os aparatos técnicos de composição audiovisual. Analisamos os diálogos e sua conformação diante dos signos da série.

A metodologia a ser utilizada é a postulada por Umberto Eco em "Obra Aberta". O autor afirma que toda obra de arte dá margem para diferentes significados, que são apreendidos de forma variada de acordo com quem a analisa: "a obra de arte é uma mensagem fundamentalmente ambígua, uma pluralidade de significados que convivem num só significante. [...] tal ambiguidade se torna - nas poéticas contemporâneas - uma das funcionalidades explícitas da obra [...]" (ECO, 1976, p.22).

A obra, assim, é capaz de fornecer interpretações simbólicas, na medida em que o espectador realiza uma decodificação daquilo que vê: uma fala de um diálogo da série, por exemplo, tem seu significado dentro da obra; o espectador, a partir dela, é capaz de decodificar a mensagem de forma mais ampla, atingindo até mesmo o universo dos símbolos, que estão presentes no imaginário da sociedade, da cultura em que está inserido. 


\section{míDiA

Eco propõe, então, pensarmos a obra como uma forma, ou seja, uma totalidade orgânica oriunda da fusão de níveis de experiência anterior (como emoções, temas, matérias, argumentos). A forma é, então, uma obra realizada, "ponto de chegada de uma produção e ponto de partida de uma consumação que - articulando-se - volta a dar vida, sempre e de novo, à forma inicial, através de perspectivas diversas" (ECO, 1976, p.28).

Mas como apreendermos os sentidos possíveis que a obra nos oferece? Eco discute, então, questões sobre o universo do "sinal" e o universo do "sentido". Para ele, a adoção do homem como destinatário de uma mensagem abre um

processo de significação, porque o sinal não é mais uma série de unidades discretas computáveis em bit de informação, mas uma forma significante que o destinatário humano deverá encher de significado. Passamos de uma teoria matemática da informação para uma teoria geral da comunicação, ou semiologia (ECO, 1976, p.111).

São, portanto, os sinais que o destinatário vai receber que vão permiti-lo atribuir um sentido ao que vê, ou seja, uma das leituras possíveis que a obra oferece. O sentido é o processo dinâmico formado pelas mudanças que ocorrem na relação entre um signo e seus significados (a relação pode crescer, mudar, transformar-se). Este processo originário do sentido é constante e está atrelado, portanto, ao receptor da mensagem.

Dessa maneira, os sentidos oferecidos por Game of Thrones serão apreendidos, aqui, através dos diálogos entre os personagens, movimentos por si só informativos e capazes de indicar determinadas situações. Vai ser possível, assim, entender as identidades assumidas por Jon Snow durante as três temporadas da série, bem como suas reações diante das circunstâncias em que se encontra.

\section{As identidades de Jon Snow}

Na primeira temporada, conhecemos Jon Snow (Figura 1), filho bastardo de Ned Stark, fato que carrega de forma negativa. 


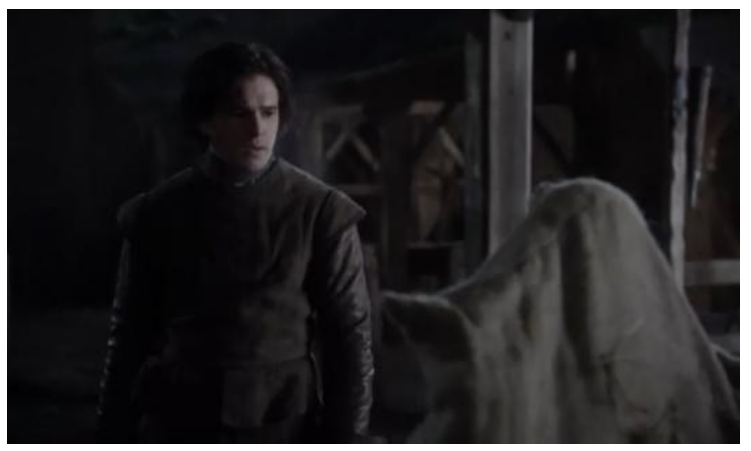

Figura 1 - Jon Snow, filho bastardo de Ned Stark

Um conselho de Tyrion Lannister (Peter Dinklage) é que o faz aceitar melhor sua condição de filho ilegítimo. A conversa gira em torno da necessidade de Jon assumir sua identidade como forma de proteção na sociedade da série:

JON. Você é Tyrion Lannister, irmão da rainha?

TYRION. Meu maior feito. E você é o bastardo de Ned Stark, não é? Eu o ofendi? Desculpe. Mas você é o bastardo.

JON. Lorde Eddard Stark é meu pai.

TYRION. E a senhora Stark não é sua mãe, o que faz de você um bastardo. Vou darlhe um conselho, bastardo. Nunca esqueça quem você é. O resto do mundo não esquecerá. Use isto como uma armadura, assim nunca poderá ser usado para feri-lo (GAME..., 2012).

Jon vê na Patrulha da Noite uma válvula de escape da sua realidade. Inspirado em seu tio Benjen, decide ingressar na irmandade, desejoso de se encontrar em um novo local. A ideia surge de uma conversa que tem com o tio, durante um banquete oferecido pelos Starks à família real.

BENJEN. Por que não está no banquete?

JON. A senhora Stark achou que insultaria a família real ter um bastardo entre eles. 
BENJEN. Sempre é bem-vindo na Muralha. Nunca recusaram um lugar a um bastardo lá.

JON. Então me leve junto quando retornar. [...] O pai deixaria se você pedisse. Sei que deixaria. [...] Estou pronto para o seu juramento (GAME..., 2012).

Jon vai, então, para a Muralha. Apesar da busca pela identidade de Irmão Juramentado, sua condição de bastardo não o abandona. Isso fica claro em um diálogo que trava com seu colega da patrulha, Samwell Tarly (John Bradley), acerca do celibato adotado pelos integrantes da Patrulha. Jon afirma nunca ter tido relações íntimas com nenhuma mulher.

JON. Já cheguei bem perto uma vez. Estava sozinho num quarto com uma garota nua, mas... [...] Qual é meu nome?

SAM. Jon Snow.

JON. E por que meu sobrenome é Snow?

SAM. Porque você é um bastardo do norte.

JON. Nunca conheci minha mãe. Meu pai não me disse nem o nome dela. Não sei se ela está viva ou morta. Não sei se é uma mulher nobre ou a esposa de um pescador. Ou uma prostituta. Então eu sentei lá no bordel e Ros tirou as roupas. Mas eu não pude fazer. Porque tudo que eu conseguia pensar era que se eu a engravidasse e ela tivesse a criança, outro bastardo chamado Snow? Não é uma vida boa para uma criança (GAME..., 2012).

A Patrulha da Noite é formada somente por homens, e muitos deles, em sua vida, foram criminosos. Geralmente é dada uma escolha quando o delinquente é pego, e ele pode pedir para vestir o negro, isto é, ser enviado para a Muralha. Ao se tornar membro da Patrulha, o indivíduo deve deixar de lado toda a sua vida passada, sua identidade, quem ele era, conforme explica o Senhor Comandante Mormont (James Cosmo):

Vieram a nós como bandidos, caçadores furtivos, estupradores, assassinos, ladrões. Vieram sozinhos, algemados, sem amigos ou honra. Vieram dos ricos, vieram da pobreza. Alguns têm nomes de Casas orgulhosas, outros nomes de bastardos e outros nenhum nome. Mas não importa. Isso tudo ficou no passado. Aqui... $\mathrm{Na}$ muralha... Somos todos de uma Casa. [...] Aprenderam as palavras de seus votos. Pensem cuidadosamente antes de falá-los. A pena por deserção é a morte (GAME..., 2012). 
Dessa maneira, os integrantes da Patrulha possuem uma serie de caracteristicas que os diferenciam dos demais habitantes de Westeros. A delimitação sobre o que é ser um vigilante da Muralha é expressa no juramento da irmandade:

[...] A noite chega e agora começa a minha vigília. Não terminará até a minha morte. Não tomarei esposa, não possuirei terras, não gerarei filhos. Não usarei coroas e não conquistarei glórias. Viverei e morrerei no meu posto. Sou a espada na escuridão. Sou o vigilante nas muralhas. Sou o escudo que defende os reinos dos homens. Dou a minha vida e a minha honra à Patrulha da Noite, por esta noite e por todas as noites que estão por vir (GAME..., 2012).

Os votos de Jon e sua identidade são postos à prova quando uma guerra é iniciada em Westeros. Com a execução de seu pai, seu irmão Robb Stark (Richard Madden) une o norte e marcha para o sul, a fim de travar batalha contra os Lannisters. Jon tenta fugir da Muralha, mas é alcançado pelos seus colegas, que o impedem de se tornar um desertor lembrando-o que sua família agora é a Patrulha da Noite. Tudo o que viveu anteriormente e sua identidade Stark devem ser relegados à memória e sua atenção deve se voltar para a Irmandade. Jon desiste da fuga e, neste momento, opta pela identidade de Irmão Juramentado, ou, como ele mesmo diz de um homem da Patrulha da Noite (Figura 2).

Assim, ingressa no grupo que sai da Muralha para procurar patrulheiros desaparecidos e verificar se os selvagens planejam um ataque à fortaleza. Os homens da Patrulha, ao sair da Muralha, cruzam a fronteira que os separa de outros povos, tornando-se passíveis de contato com a alteridade. Ao adentrar o desconhecido, mudanças podem ser exigidas pelas circunstâncias para que haja sobrevivência.

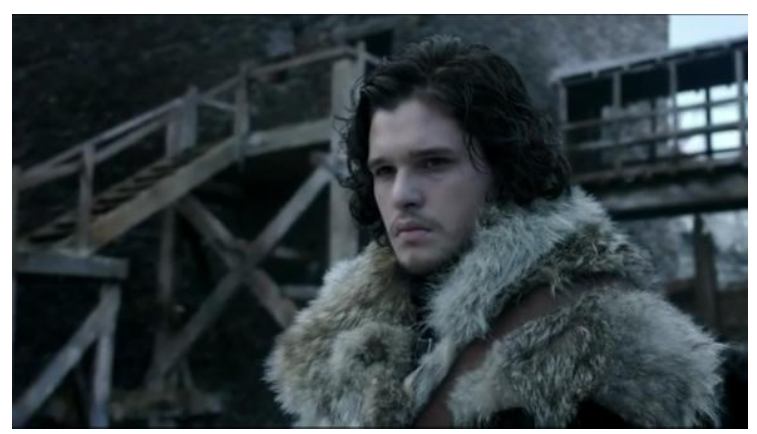




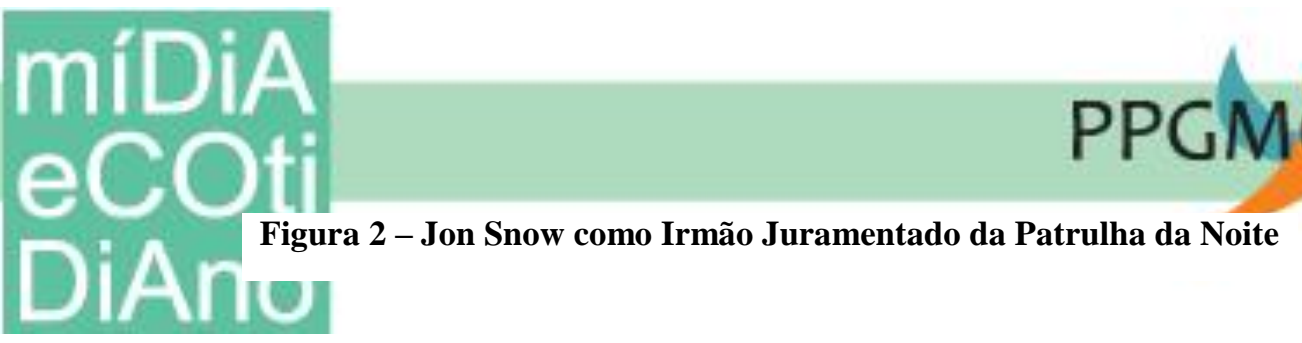

$\mathrm{Na}$ segunda temporada, Jon sai em expedição com o pequeno grupo encabeçado por Qhorin Meia-Mão, que visa descobrir informações sobre Mance Rayder. No caminho, os patrulheiros matam alguns selvagens, mas Jon não consegue pôr fim à vida de Ygritte, que estava no bando. Ela acaba sendo feita refém. Um diálogo entre Jon e a prisioneira demarca algumas diferenças existentes entre os Irmãos Juramentados da Patrulha da Noite e os selvagens - as identidades de cada um sendo estabelecidas pelas diferenças.

YGRITTE. Você acha que somos selvagens porque não vivemos em castelos. É verdade que não fazemos aço tão bem quanto vocês, mas somos livres. [...] Não servimos a um rei de merda só porque o seu pai era rei. [...] Nós escolhemos Mance Rayder para nos liderar. Ele era um corvo, como você. Mas ele queria ser livre. Você pode ser livre também. Você não precisa passar a vida obedecendo a ordens de velhos. Acorde quando quiser acordar. Posso mostrar-lhe onde pescar e onde caçar. Construa uma cabana e encontre uma mulher. Você é um rapaz bonito. Garotas arrancariam os olhos umas das outras para ficarem nuas com você (GAME..., 2013).

Ygritte pretende mostrar a seu captor o quanto a identidade de corvo, como ela diz, aprisiona o sujeito. Ser selvagem, por outro lado, é ter liberdade de escolha e ação, o que, para ela, é melhor. Com as constantes conversas, a jovem consegue escapar, e Jon cai em uma emboscada dos selvagens, que também capturaram Qhorin. O Meia-Mão só vê como saída para ajudar a Patrulha se Jon se infiltrar entre os selvagens e descobrir seus planos.

QHORIN. Mance vai atacar a Muralha. Um homem nosso infiltrado em seu exército valerá por mil lutando contra ele.

JON. Nunca confiarão em mim.

QHORIN. Talvez confiem. Se fizer o que é preciso.

JON. O quê?

QHORIN. (gritando): Como é saber que aqueles homens morreram para você fugir com a selvagem?

JON. Eu não...

QHORIN. Eu nunca deveria confiar num bastardo de um traidor (GAME..., 2013). 
- Qhorin grita para fazer os selvagens acreditar que está contra Jon. Para isso, çmeça a lutar contra ele e a provocá-lo, até que Jon, em um instinto de sobrevivência durante a briga, o mata. Qhorin só diz uma frase antes de morrer: "Somos os vigilantes na Muralha" (GAME..., 2013). A colocação mostra para Jon que o objetivo do Irmão, ao iniciar a briga, era que o jovem o matasse. Essa seria a prova definitiva para convencer os selvagens de que Jon deseja ser um deles. A morte de Qhorin, portanto, aparenta a mudança de identidade de Jon.

Devemos notar, porém, que a nova identidade assumida pelo personagem é fruto das circunstâncias e, consequentemente, uma questão de sobrevivência: se Jon não ingressasse no bando dos selvagens, seria morto e, provavelmente, os outros Irmãos também, já que Mance Rayder realmente planejava atacar a Muralha. E como essa nova identidade construída será apresentada durante a terceira temporada?

Logo no primeiro episódio, Jon é levado à tenda do Rei Para-Lá-da-Muralha para ser questionado e, ao fim da conversa, é aceito no grupo (Figura 3):

MANCE. Por que quer juntar-se a nós, Jon Snow?

JON. Eu quero ser livre.

MANCE. Não, acho que não. Acho que o que mais quer é ser um heroi. Perguntarei uma última vez: por que quer juntar-se a nós?

JON. Paramos na Fortaleza de Craster a caminho do Norte. Eu vi...

MANCE. Viu o quê?

JON. Vi Craster levar seu próprio filho e deixa-lo na floresta. Vi o que o levou.

MANCE. Está me dizendo que viu um deles [caminhantes brancos]? E por que isso o faria desertar seus irmãos?

JON. Porque quando contei ao Senhor Comandante, ele já sabia. Milhares de anos atrás, os Primeiros Homens enfrentaram os Caminhantes Brancos e os derrotaram. Quero lutar pelo lado que luta pelos vivos. Vim ao lugar certo?

MANCE. Precisaremos encontrar um novo manto para você (GAME..., 2013).

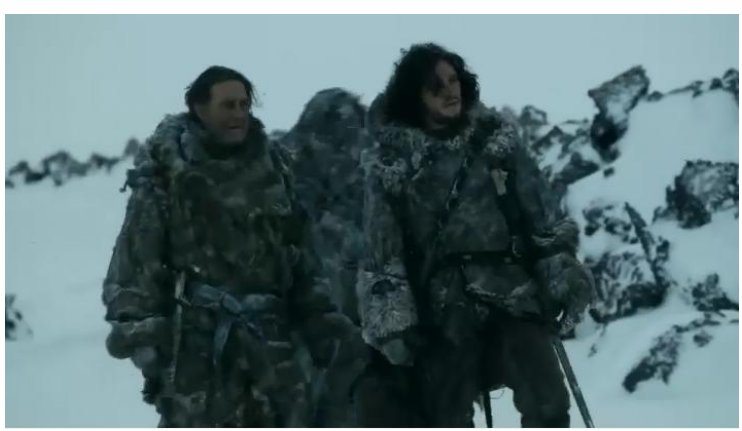


Enquanto assumiu sua identidade de selvagem, Jon foi posto à prova diversas vezes, muitas

Figura 3 - Jon Snow como selvagem ao lado de Mance Rayder

relacionadas

ao fato de ser obrigado a dar informações detalhadas sobre as defesas da Muralha, quantos homens a guardam em cada ponto, quais as estratégias utilizadas. Mas o verdadeiro teste ocorre quando Ygritte o seduz e ele quebra um dos maiores juramentos da Patrulha da Noite: o celibato (Figuras 4 e 5).

YGRITTE. Você ainda é um corvo? É hora de provar-se [vai se despindo enquanto fala]. JON. Ygritte...

YGRITTE. Você jurou alguns votos. Quero que os quebre. Quero que me veja. Completamente.

JON. Não deveríamos.
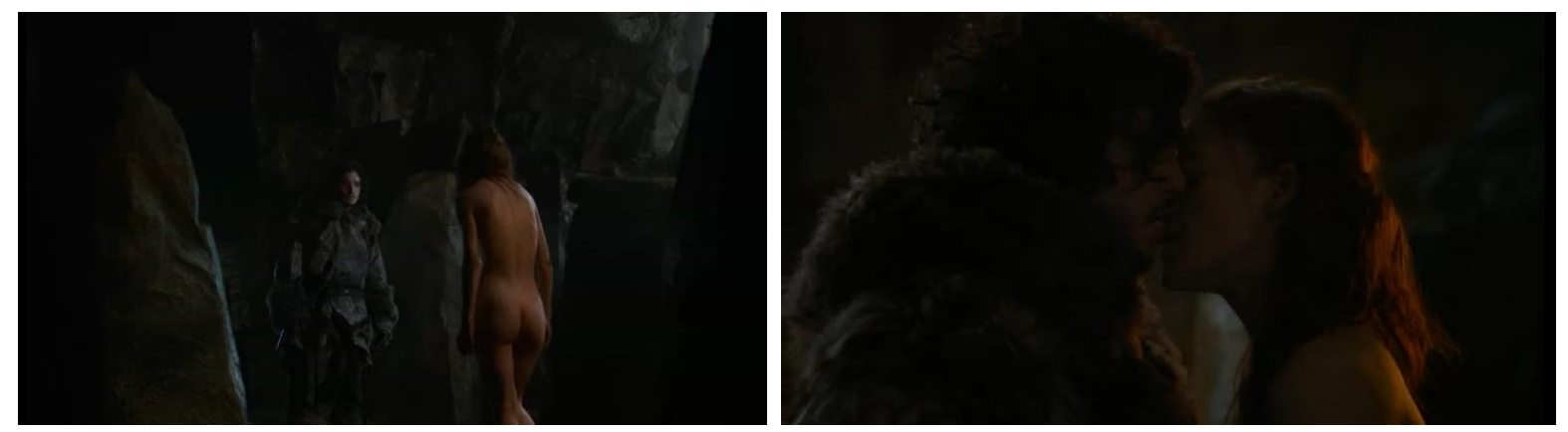

Figuras 4 e 5 - Jon quebra o maior juramento da Patrulha com Ygritte

YGRITTE.

Deveríamos.

$[\ldots]$

JON. Não houve mais ninguém. Somente você.

YGRITTE. Uma donzela. Você era uma donzela.

JON. Eu era um homem da Patrulha da Noite (GAME..., 2013).

Apesar de conseguir manter sua nova identidade, Jon revela-se ainda um Irmão Juramentando quando os selvagens o mandam matar um homem que cria cavalos para a 


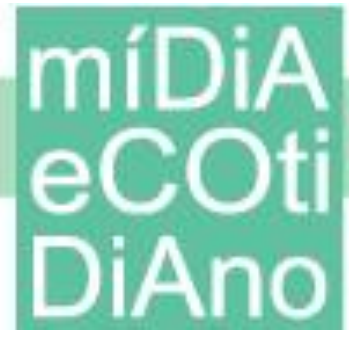

Patrulha e ele não comete o assassinato. É acusado então de nunca ter deixado de ser um 'corvo', e foge.

No caminho, é alcançado por Ygritte e os dois têm um último diálogo:

JON. Ygritte, eu não tive escolha! Você sempre soube quem eu era, o que eu sou. Devo ir para casa agora. Sei que não me machucará.

YGRITTE. Você não sabe nada, Jon Snow.

JON. Eu sei algumas coisas. Sei que a amo. Sei que você me ama. Mas devo ir para casa agora (GAME..., 2013).

A selvagem atira três flechas, que acertam Jon. No entanto, ele consegue fugir e voltar para a Patrulha. Mas não sem ferimentos. Não sem marcas.

\section{Considerações Finais}

Por muitos anos, produções audiovisuais foram capazes de reproduzir o que se passava na sociedade, muitas vezes através do predomínio de determinadas nações e posicionamentos. Seja no cinema hollywoodiano ou nas produções televisuais, as situações representadas podem nos auxiliar a entender a contemporaneidade, como também a sociedade atual pode nos fornecer os subsídios para analisarmos as produções midiáticas.

Em nosso estudo, vimos que as do personagem Jon Snow podem ser tomadas como representações da sociedade atual, composta por múltiplas identidades e sujeitos que se intercambiam entre elas, com fluidez e mudanças constantes. Vimos que as identidades são fruto de narrativas que geram noções de pertencimento ou não a determinado grupo ou nação. No caso de Jon, a primeira identidade apresentada é a do garoto bastardo, que nem ao menos conhece sua mãe. Seu desejo de mudança é tanto que se alista na Patrulha da Noite em busca de uma identidade capaz de lhe dar orgulho e, principalmente, sensação de pertencimento (ele não se sentia membro da família Stark; era sempre um intruso).

A Patrulha, com suas especificidades, molda as identidades dos que nela ingressam: são homens com personalidades e histórias diferentes, mas que, ao prestar seu juramento, se tornam Irmãos Juramentados. Há expectativas acerca da Irmandade, e Jon procura atendê-las 


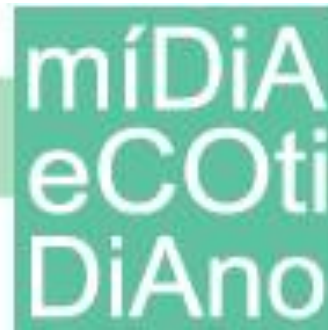

na construção de sua nova identidade. Porém, ele é posto em circunstâncias que exigem uma mudança de comportamento e, principalmente, identidade: viver como desertor e se juntar a selvagens, inimigos dos patrulheiros.

Como já dissemos, todavia, essa nova identidade assumida por Jon é forjada e, portanto, fruto de uma narrativa que ele faz sobre si para convencer seus novos companheiros. Ela é construída através de atos e provas, fornecendo a fixação de sua nova imagem. O único interdito que por Jon ficaria intacto - o celibato - é quebrado com Ygritte. Há, assim, uma hybris, uma falha trágica: Jon cai em tentação. Ficar com Ygritte representaria sua liberdade pessoal, sua desvinculação da vida de Irmão Juramentado, mas a verdadeira identidade de Jon não permite que isto aconteça.

A terceira temporada termina com Jon flechado pelo amor de Ygritte. O encerramento deixa o espectador em suspenso, gancho que permitirá vermos na próxima temporada a grande dúvida edipiana de Jon, uma vez que, mesmo aparentemente, ele conseguiu criar uma identidade próxima à sua alteridade.

Assim, apesar da ambiência medieval, a narrativa de Game of Thrones apresenta, no fundo, o homem contemporâneo e suas angústias, o que dá à série um interessa extra para ser analisada no âmbito da Comunicação. O público, conforme aponta Umberto Eco, dá sentido à obra; e, se o público de hoje é fragmentado, podemos apreender sentidos condizentes com a contemporaneidade. Dessa maneira, identificamos em Game of Thrones, especificamente nas nuances de Jon, uma produção pós-moderna que, devido a esta característica, é capaz de permitir leituras globalizadas. Afinal, a crise da identidade está presente na maioria das sociedades atuais.

\section{Referências}

BHABHA, Homi. O local da cultura. Belo Horizonte: Editora UFMG, 1998. 
ECO, Umberto. Obra aberta. São Paulo: Perspectiva, 1976.

FERRO, Marc. O filme: uma contra análise da sociedade. Disponível em:

<http://www.educacaopublica.rj.gov.br/oficinas/historia/reverso/downloads/MarcFerro.pdf>. Acesso em 28 jul. 2013.

GAME of Thrones - Primeira temporada completa. Direção: David Benioff e D.B. Weiss. EUA: Warner Home Video, 2012. 5 DVDs.

GAME of Thrones - Segunda temporada completa. Direção: David Benioff e D.B. Weiss. EUA: Warner Home Video, 2013. 5 DVDs.

GAME of Thrones - Terceira temporada completa. Dir. David Benioff e D.B. Weiss. EUA: HBO, 2013. Série de TV.

HALL, Stuart. A identidade cultural na pós-modernidade. 7. ed. Rio de Janeiro: DP\&A, 2003.

KELLNER, Douglas. A cultura da mídia. Bauru: EDUSC, 2001.

MARTÍN-BARBERO, Jesús. Dos meios às mediações: comunicação, cultura e hegemonia. Trad. Ronald Polito; Sérgio Alcides. Rio de Janeiro: UFRJ, 2003.

SILVA, Tomaz Tadeu da. A produção social da identidade e da diferença. In: SILVA, Tomaz Tadeu da (org). Identidade e diferença: a perspectiva dos estudos culturais. Petrópolis: Vozes, 2011.

SZKLARZ, Eduardo. Corpo estranho. A Guerra dos Tronos: o guia definitivo da saga (Superinteressante Coleções), São Paulo, n.314, p. 40-41, jan. 2013. 


\section{DiAno}

WOODWARD, Kathryn. Identidade e diferença: uma introdução teórica e conceitual. In: SILVA, Tomaz Tadeu da (org). Identidade e diferença: a perspectiva dos estudos culturais. Petrópolis: Vozes, 2011.

ZIZEK, Slavoj. El minority report de gerhard schroeder y sus consecuencias. Disponível em: <http://www.geocities.ws/zizekencastellano/artSchroeer.html>. Acesso em 28 jul. 2013. 